\title{
Functionalized Poly(tetramethyl-1,4-silphenylenesiloxane) with Pendant Hydroxyl Groups
}

\author{
By Yuki YANAI, ${ }^{1}$ Takahiro SASAKI, ${ }^{1}$ Yumiko OTOMO,${ }^{1}$ Shizuka OTA, ${ }^{1}$ \\ Yu NAGASE, ${ }^{2}$ and Nobukatsu NEMOTO ${ }^{1, *}$
}

\begin{abstract}
Novel functionalized poly(tetramethyl-1,4-silphenylenesiloxane) with pendant hydroxyl groups, i.e., poly[2,5-bis(2hydroxyethoxy)-tetramethyl-1,4-silphenylenesiloxane] (P1), was synthesized and characterized by differential scanning calorimetry (DSC), thermogravimetry (TG), and X-ray diffraction analysis. P1 was obtained via catalytic deprotectivehydrogenation of poly[2,5-bis(2-benzyloxyethoxy)-tetramethyl-1,4-silphenylenesiloxane] (PreP1), which had been obtained by catalytic polycondensation of 2,5-bis(2-benzyloxyethoxy)-1,4-bis(dimethylhydroxysilyl)benzene (M1) in benzene. P1 was revealed to be an amorphous polymer as deduced from DSC as well as X-ray diffraction measurement, and soluble in highly polar solvents as ethanol and methanol in which poly(tetramethyl-1,4-silphenylenesiloxane) (1,4-PTMPS) is insoluble. The glass transition temperature $\left(T_{\mathrm{g}}\right)$ of $\mathbf{P 1}$ was determined to be $73^{\circ} \mathrm{C}$ from DSC, which was much higher than that of $1,4-$ PTMPS $\left(-20^{\circ} \mathrm{C}\right)$, indicating that the intermolecular and/or intramolecular hydrogen bondings based on hydroxyl groups restricted the mobility of the main chain. The temperature at $5 \%$ weight loss $\left(T_{\mathrm{d} 5}\right)$ of $\mathbf{P 1}\left(290^{\circ} \mathrm{C}\right)$ determined by TG was lower than that of 1,4-PTMPS, indicating that the oxyethylene and/or alcoholic-hydroxyl moieties decline the thermostability; however, the obtained P1 would promise to be a new reactive-polymer with hydroxyl moieties to develop new functional materials.

KEY WORDS: Hydroxyl Group / Polysiloxanes / Polycondensation / Reactive Polymer / Thermal Properties /
\end{abstract}

Generally, the use of polysiloxane derivatives in coating of substrates would be effective in the improvement of surface properties owing to the particular characteristics of polysiloxanes such as hydrophobicity based on alkyl side chain, thermostability, stability against atomic oxygen, and physiological inertness. ${ }^{1}$ Meanwhile, the interactions of polysiloxane with the other kinds of substrates are so weak to reduce adhesion strength because of the low polarity and surface energy of polysiloxane, resulting in the low stability of the coated substrates. ${ }^{2}$

On the other hand, poly(tetramethyl-1,4-silphenylenesiloxane) (1,4-PTMPS) is the representative polymer where an aromatic moiety is incorporated into the polysiloxane backbone ${ }^{3-5}$ which would presumably improve the good properties of polysiloxane, especially the thermostability. It has been reported that the properties of poly(tetramethylsilarylenesiloxane) derivatives depend on the kind of arylene moiety, ${ }^{4-12}$ the substituted position of dimethylsilyl groups ${ }^{8,9,13}$ as well as the substituent ${ }^{5,14-16}$ on the arylene moiety. For instance, 1,4PTMPS derivatives having oxyethylene groups on the phenylene moiety have been reported to exhibit the lower thermostability compared with 1,4-PTMPS, the crystallinity of which was mainly dependent on the oxyethylene groups on the phenylene moiety. ${ }^{14}$ In other words, the functional groups on the phenylene moiety could control the properties of PTMPS derivatives.

By the way, intermolecular and/or intramolecular hydrogen bondings have been well-known to influence various properties of polymers. Hydrogen bondings are important not only in the formation of polymer complexes to develop new materials ${ }^{17}$ but also in the increase in miscibility of polymer systems owing to the specific interactions through hydrogen bondings ${ }^{18}$ and/or to the hydrophilicity of hydroxyl groups. ${ }^{19}$ The introduction of alcoholic-hydroxyl groups into 1,4-PTMPS would enable 1,4-PTMPS derivatives to interact with the other kinds of substrates, such as a highly polar substrate. Additionally, alcoholic-hydroxyl moieties are useful as reactive groups, which can be applied in esterification and etherification to introduce various functional moieties. Therefore, 1,4-PTMPS derivatives with alcoholic-hydroxyl groups on the phenylene moiety would be applicable as a new reactive-polymer to develop new functional polymers.

From these points of view, we report here the synthesis of a new 1,4-PTMPS derivatives with alcoholic-hydroxyl groups on the phenylene moiety, i.e., poly[2,5-bis(2-hydroxyethoxy)tetramethyl-1,4-silphenylenesiloxane] (P1), as shown in Scheme 1.

The present paper also describes the results of characterization of the obtained polymers by differential scanning calorimetry (DSC) and thermogravimetry (TG) as well as $\mathrm{X}$-ray diffraction analysis.

\section{EXPERIMENTAL}

\section{Materials}

2,5-Dibromohydroquinone (1) was prepared by bromination

\footnotetext{
${ }^{1}$ Department of Materials Chemistry and Engineering, College of Engineering, Nihon University, Koriyama 963-8642, Japan

${ }^{2}$ Department of Applied Chemistry, School of Engineering, Tokai University, Hiratsuka 259-1292, Japan

*To whom correspondence should be addressed (Tel/Fax: +81-24-956-8812, E-mail: nemoto@ @ chem.ce.nihon-u.ac.jp).
} 

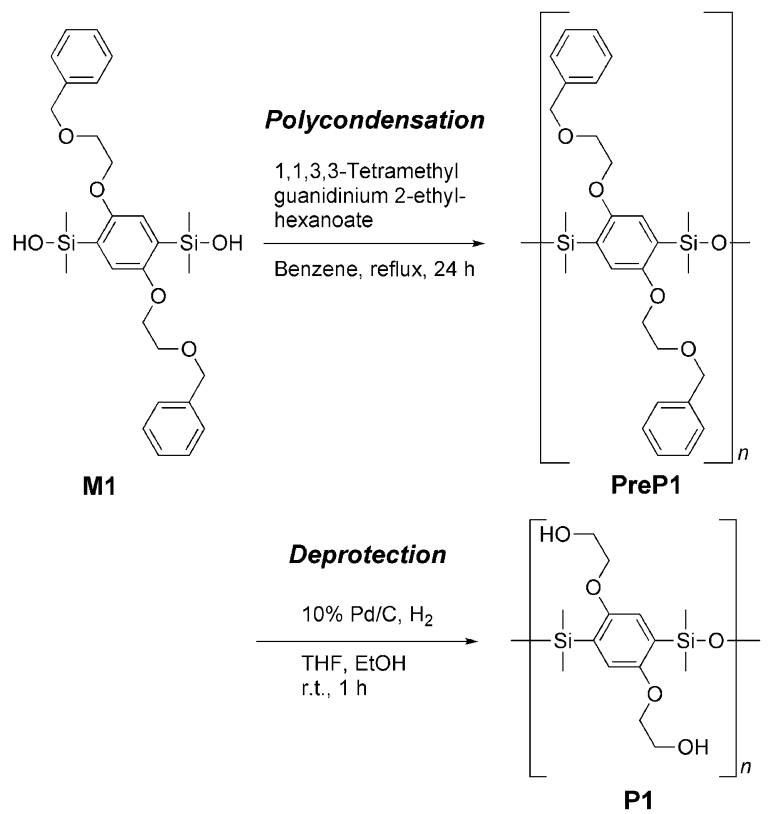

Scheme 1. Synthetic pathways for poly[2,5-bis(2-hydroxyethoxy)-tetramethyl-1,4-silphenylenesiloxane] (P1).

of hydroquinone (KANTO KAGAKU) according to the published method. ${ }^{20}$ 2-Benzyloxyethyl 4-toluenesulfonate was prepared by the reaction of 4-toluenesulfonyl chloride (Tokyo Kasei Kogyo Co., Inc.) with 2-benzyloxyethanol (Tokyo Kasei Kogyo Co., Inc.) according to the modified method in the literature. ${ }^{21}$ Magnesium, potassium hydroxide, ethanol (KANTO KAGAKU), chlorodimethylsilane (Acros organics), $5 \%$ palladium on charcoal (Escat 103, from Aldrich), and $10 \%$ palladium on charcoal (Degussa type E101 NE/W, from Aldrich) were commercially available and used as received. 1,1,3,3-Tetramethylguanidinium 2-ethylhexanoate was prepared by the literature procedures. ${ }^{8,9} 1,4$-PTMPS $\left(M_{\mathrm{n}}: 2.87 \times\right.$ $\left.10^{5}, M_{\mathrm{w}} / M_{\mathrm{n}}: 1.51\right)$ was prepared by polycondensation of $1,4-$ bis(dimethylhydroxysilyl)benzene. Benzene and tetrahydrofuran (THF) (Wako Pure Chemical Industries, Ltd.) were used after distillation over sodium.

\section{Measurements}

${ }^{1} \mathrm{H}(400 \mathrm{MHz})$ and ${ }^{13} \mathrm{C}(100 \mathrm{MHz})$ NMR spectra were recorded on a Bruker AVANCE 400F spectrometer in deuterated chloroform $\left(\mathrm{CDCl}_{3}\right)$ or dimethylsulfoxide $\left[\left(\mathrm{CD}_{3}\right)_{2} \mathrm{SO}\right]$ at ambient temperature. IR spectra were measured on a Perkin-Elmer Spectrum One FT-IR spectrometer. Melting point $\left(T_{\mathrm{m}}\right)$ and glass transition temperature $\left(T_{\mathrm{g}}\right)$ were measured on a RIGAKU ThermoPlus DSC 8230 under a nitrogen atmosphere. Thermogravimetry (TG) was performed on a RIGAKU ThermoPlus TG8110 at a heating rate of $10^{\circ} \mathrm{C} / \mathrm{min}$ under a nitrogen atmosphere. The number-average molecular weights $\left(M_{\mathrm{n}}\right)$ and the polydispersity indices $\left(M_{\mathrm{w}} / M_{\mathrm{n}}\right)$ of polymers were estimated by size-exclusion chromatography (SEC) on a SHOWA DENKO Shodex GPC-101 system with polystyrene gel columns (a pair of Shodex GPC LF-804), eluted with THF using a calibration curve of polystyrene standards. X-Ray diffraction patterns were recorded on a Philips PW1830 X-ray diffractometer, equipped with a Philips HTK-2-HC thermal controller.

\section{2,5-Bis(2-benzyloxyethoxy)-1,4-dibromobenzene [2]}

2-Benzyloxyethyl 4-toluenesulfonate $(53.70 \mathrm{~g}, 175 \mathrm{mmol})$ was added dropwise to 2,5-dibromohydroquinone $(1,13.39 \mathrm{~g}$, $50.0 \mathrm{mmol})$ and potassium hydroxide $(9.82 \mathrm{~g}, 175 \mathrm{mmol})$ dissolved in ethanol $(150 \mathrm{~mL})$ under a dry argon atmosphere. After the resulting reaction mixture was refluxed for $12 \mathrm{~h}$, it was poured into the mixture of chloroform $(200 \mathrm{~mL})$ and $\mathrm{NH}_{4} \mathrm{Cl}$ aqueous solution $(100 \mathrm{~mL})$. The organic layer was washed with another $\mathrm{NH}_{4} \mathrm{Cl}$ aqueous solution, dried over anhydrous $\mathrm{MgSO}_{4}$, and filtered. The filtrate was concentrated under reduced pressure. The residue was recrystallized from the mixed solvent of ethyl acetate/hexane to afford $\mathbf{2}$ as colorless crystals. Yield: $63 \% .{ }^{1} \mathrm{H} \mathrm{NMR} \delta$ (ppm, $\mathrm{CDCl}_{3}$, $400 \mathrm{MHz}): 3.86\left(\mathrm{t}, J=4.8 \mathrm{~Hz}, 4 \mathrm{H}\right.$, ethoxy $\left.-\mathrm{CH}_{2}-\right), 4.16(\mathrm{t}$, $J=4.8 \mathrm{~Hz}, 4 \mathrm{H}$, ethoxy $\left.-\mathrm{CH}_{2}-\right), 4.68\left(\mathrm{~s}, 4 \mathrm{H}\right.$, benzyl $\left.-\mathrm{CH}_{2}-\right)$, 7.16 (s, 2H, dibromophenylene protons), 7.27-7.40 [m, 10H, phenyl(benzyl) protons]. ${ }^{13} \mathrm{C} \mathrm{NMR} \delta$ (ppm, $\left.\mathrm{CDCl}_{3}, 100 \mathrm{MHz}\right)$ : 68.3 (ethoxy $-\mathrm{CH}_{2}-$ ), 70.1 (ethoxy $-\mathrm{CH}_{2}-$ ), 73.5 (benzyl $-\mathrm{CH}_{2}-$ ), 111.3 (phenyl carbons), 119.0 (phenyl carbons), 127.7 (phenyl carbons), 127.9 (phenyl carbons), 128.3 (phenyl carbons), 128.5 (phenyl carbons), 138.1 (phenyl carbons), 150.3 (phenyl carbons). IR (KBr, $\left.\mathrm{cm}^{-1}\right)$ : 1203 (aromatic ether), 1120 (aliphatic ether). M. p.: $98^{\circ} \mathrm{C}$.

\section{2,5-Bis(2-benzyloxyethoxy)-1,4-bis(dimethylsilyl)benzene [3]}

Chlorodimethylsilane $(3.41 \mathrm{~g}, 36.0 \mathrm{mmol})$ was added dropwise to magnesium $(0.875 \mathrm{~g}, 36.0 \mathrm{mmol})$ in dry THF $(15 \mathrm{~mL})$ at $60{ }^{\circ} \mathrm{C}$ under a dry argon atmosphere. To this mixture, $2(6.43 \mathrm{~g}$, $12.0 \mathrm{mmol})$ in dry THF $(30 \mathrm{~mL})$ was added dropwise and the reaction mixture was refluxed for $24 \mathrm{~h}$. Then, the resulting reaction mixture was poured into the mixture of ethyl acetate $(100 \mathrm{~mL})$ and $0.5 \mathrm{~mol} / \mathrm{L} \mathrm{HCl}$ aqueous solution $(100 \mathrm{~mL})$. The organic layer was washed with saturated $\mathrm{NaHCO}_{3}$ aqueous solution, dried over anhydrous $\mathrm{MgSO}_{4}$, and filtered. The filtrate was concentrated under reduced pressure. The residue was dissolved in hexane and purified by silica gel chromatography eluted with the mixed solvent of hexane/chloroform (vol. ratio $2: 1, R_{f}$ value: 0.67$)$. The collected fraction of the purified material was concentrated under reduced pressure. The residue was recrystallized from hexane to afford $\mathbf{3}$ as colorless crystals. Yield: $77 \%$. ${ }^{1} \mathrm{H}$ NMR $\delta$ (ppm, $\left.\mathrm{CDCl}_{3}, 400 \mathrm{MHz}\right): 0.34(\mathrm{~d}$, $\left.J=3.8 \mathrm{~Hz}, 12 \mathrm{H}, \mathrm{Si}-\mathrm{CH}_{3}\right), 3.83(\mathrm{t}, J=5.0 \mathrm{~Hz}, 4 \mathrm{H}$, ethoxy $-\mathrm{CH}_{2}-$ ), 4.14 (t, $\mathrm{J}=5.0 \mathrm{~Hz}, 4 \mathrm{H}$, ethoxy $-\mathrm{CH}_{2}-$ ), 4.38 (sept, $J=3.8 \mathrm{~Hz}, 2 \mathrm{H}, \mathrm{Si}-H), 4.62\left(\mathrm{~s}, 4 \mathrm{H}\right.$, benzyl $\left.-\mathrm{CH}_{2}-\right), 6.92[\mathrm{~s}$, $2 \mathrm{H}$, bis(dimethylsilyl)phenylene protons], 7.26-7.38 [m, 10H, phenyl(benzyl) protons]. ${ }^{13} \mathrm{C} \mathrm{NMR} \delta$ (ppm, $\mathrm{CDCl}_{3}, 100 \mathrm{MHz}$ ): $-3.67\left(\mathrm{Si}-\mathrm{CH}_{3}\right), 67.9$ (ethoxy $-\mathrm{CH}_{2}-$ ), 69.0 (ethoxy $-\mathrm{CH}_{2}-$ ), 73.4 (benzyl $-\mathrm{CH}_{2}-$ ), 117.8 (phenyl carbons), 127.6 (phenyl carbons), 127.7 (phenyl carbons), 128.4 (phenyl carbons), 128.5 (phenyl carbons), 138.1 (phenyl carbons), 157.5 (phenyl carbons). IR (KBr, cm $\left.{ }^{-1}\right)$ : $2135(\mathrm{Si}-\mathrm{H}), 1206$ (aromatic ether), 1119 (aliphatic ether). M. p.: $71^{\circ} \mathrm{C}$. 


\section{2,5-Bis(2-benzyloxyethoxy)-1,4-bis(dimethylhydroxysilyl)- benzene [M1]}

In an ice bath, $3(2.50 \mathrm{~g}, 5.05 \mathrm{mmol})$ in dry THF $(2.5 \mathrm{~mL})$ was added dropwise to $5 \%-\mathrm{Pd}$ on $\mathrm{C}(0.0075 \mathrm{~g})$ with $\mathrm{H}_{2} \mathrm{O}$ $(0.27 \mathrm{~g}, 15.0 \mathrm{mmol})$ in THF $(1.2 \mathrm{~mL})$. The reaction mixture was stirred at ambient temperature for $12 \mathrm{~h}$ and filtered. The filtrate was concentrated under reduced pressure and the residue was recrystallized from benzene to afford $\mathbf{M 1}$ as colorless crystals. Yield: 93\%. ${ }^{1} \mathrm{H}$ NMR $\delta$ (ppm, $\mathrm{CDCl}_{3}$, $400 \mathrm{MHz}$ ): 0.37 (s, $\left.12 \mathrm{H}, \mathrm{Si}-\mathrm{CH}_{3}\right), 3.73(\mathrm{t}, J=4.8 \mathrm{~Hz}, 4 \mathrm{H}$, ethoxy $\left.-\mathrm{CH}_{2}-\right), 4.14\left(\mathrm{t}, \mathrm{J}=4.8 \mathrm{~Hz}, 4 \mathrm{H}\right.$, ethoxy $\left.-\mathrm{CH}_{2}-\right), 4.26$ (s, 2H, Si-OH), 4.64 (s, 4H, benzyl $-\mathrm{CH}_{2}-$ ), $6.86[\mathrm{~s}, 2 \mathrm{H}$, bis(dimethylhydroxysilyl)phenylene protons], 7.28-7.40 [m, $10 \mathrm{H}$, phenyl(benzyl) protons]. ${ }^{13} \mathrm{C} \mathrm{NMR} \delta$ (ppm, $\mathrm{CDCl}_{3}$, $100 \mathrm{MHz}$ ): $0.0\left(\mathrm{Si}-\mathrm{CH}_{3}\right), 68.1$ (ethoxy $-\mathrm{CH}_{2}-$ ), 68.5 (ethoxy $-\mathrm{CH}_{2}-$ ), 73.2 (benzyl $-\mathrm{CH}_{2}-$ ), 117.6 (phenyl carbons), 127.8 (phenyl carbons), 127.9 (phenyl carbons), 128.5 (phenyl carbons), 131.6 (phenyl carbons), 137.1 (phenyl carbons), 157.8 (phenyl carbons). IR ( $\left.\mathrm{KBr}, \mathrm{cm}^{-1}\right)$ : 3550-3000 (br, $-\mathrm{OH}$ ), 1193 (aromatic ether), 1111 (aliphatic ether). M. p.: $88^{\circ} \mathrm{C}$.

\section{Poly[2,5-bis(2-benzyloxyethoxy)-tetramethyl-1,4-silphenyl-} enesiloxane] [PreP1]

1,1,3,3-Tetramethylguanidinium 2-ethylhexanoate $(0.02 \mathrm{~g})$ was added to M1 $(1.50 \mathrm{~g}, 2.85 \mathrm{mmol})$ dissolved in dry benzene $(15.0 \mathrm{~mL})$ under a dry atmosphere. After the resulting reaction mixture was refluxed for $24 \mathrm{~h}$, it was poured into methanol $(300 \mathrm{~mL})$ to isolate the resulting polymer as white precipitate. The precipitate was dried at $60^{\circ} \mathrm{C}$ under reduced pressure to afford PreP1 as colorless solid. Yield: $91 \%$. ${ }^{1} \mathrm{H}$ NMR $\delta\left(\mathrm{ppm}, \mathrm{CDCl}_{3}, 400 \mathrm{MHz}\right): 0.40\left(12 \mathrm{H}, \mathrm{s}, \mathrm{Si}-\mathrm{CH}_{3}\right)$, 3.65-3.75 (4H, m, ethoxy $\left.-\mathrm{CH}_{2}-\right), 3.95-4.05(4 \mathrm{H}, \mathrm{m}$, ethoxy $\left.-\mathrm{CH}_{2}-\right), 4.50\left(4 \mathrm{H}\right.$, s, benzyl $\left.-\mathrm{CH}_{2}-\right), 7.05[2 \mathrm{H}, \mathrm{s}$, bis $(\mathrm{di}-$ methylsilyl)phenylene protons], 7.25-7.35 $[10 \mathrm{H}, \mathrm{m}$, phenyl(benzyl) protons]. ${ }^{13} \mathrm{C}$ NMR $\delta$ (ppm, $\mathrm{CDCl}_{3}, 100 \mathrm{MHz}$ ): 1.87 $\left(\mathrm{Si}-\mathrm{CH}_{3}\right.$ ), 67.3 (ethoxy $-\mathrm{CH}_{2}-$ ), 69.0 (ethoxy $-\mathrm{CH}_{2}-$ ), 73.2 (benzyl $-\mathrm{CH}_{2}-$ ), 116.7 (phenyl carbons), 127.5 (phenyl carbons), 127.7 (phenyl carbons), 128.3 (phenyl carbons), 130.2 (phenyl carbons), 138.1 (phenyl carbons), 156.9 (phenyl carbons). IR (Film on $\mathrm{KBr}, \mathrm{cm}^{-1}$ ): 1248 (aromatic ether), 1105 (aliphatic ether), $1070(\mathrm{Si}-\mathrm{O})$.

Synthesis of Poly[2,5-bis(2-hydroxyethoxy)-tetramethyl-1,4silphenylenesiloxane] [P1] by Deprotective Hydrogenation of PreP1

In a reaction flask, $0.404 \mathrm{~g}$ of $10 \%-\mathrm{Pd}$ on $\mathrm{C}$ was added to $0.300 \mathrm{~g}$ ( $0.59 \mathrm{mmol})$ of PreP1 dissolved in $36 \mathrm{~mL}$ of THF and $4 \mathrm{~mL}$ of ethanol. Under an atmospheric pressure, hydrogen was supplied to the reaction mixture from a balloon with stirring for $1 \mathrm{~h}$ at ambient temperature. The reaction mixture was filtered and the filtrate was poured into $300 \mathrm{~mL}$ of hexane to isolate the resulting polymer as white precipitate. The precipitate was dried at $60^{\circ} \mathrm{C}$ under reduced pressure to afford $\mathbf{P 1}$ as colorless powder solid. Yield: $86 \% .{ }^{1} \mathrm{H}$ NMR $\delta\left[\mathrm{ppm},\left(\mathrm{CD}_{3}\right)_{2} \mathrm{SO}\right.$, $400 \mathrm{MHz}$ ]: $0.36\left(12 \mathrm{H}, \mathrm{s}, \mathrm{Si}-\mathrm{CH}_{3}\right), 3.55-3.75(4 \mathrm{H}, \mathrm{m}$, ethoxy
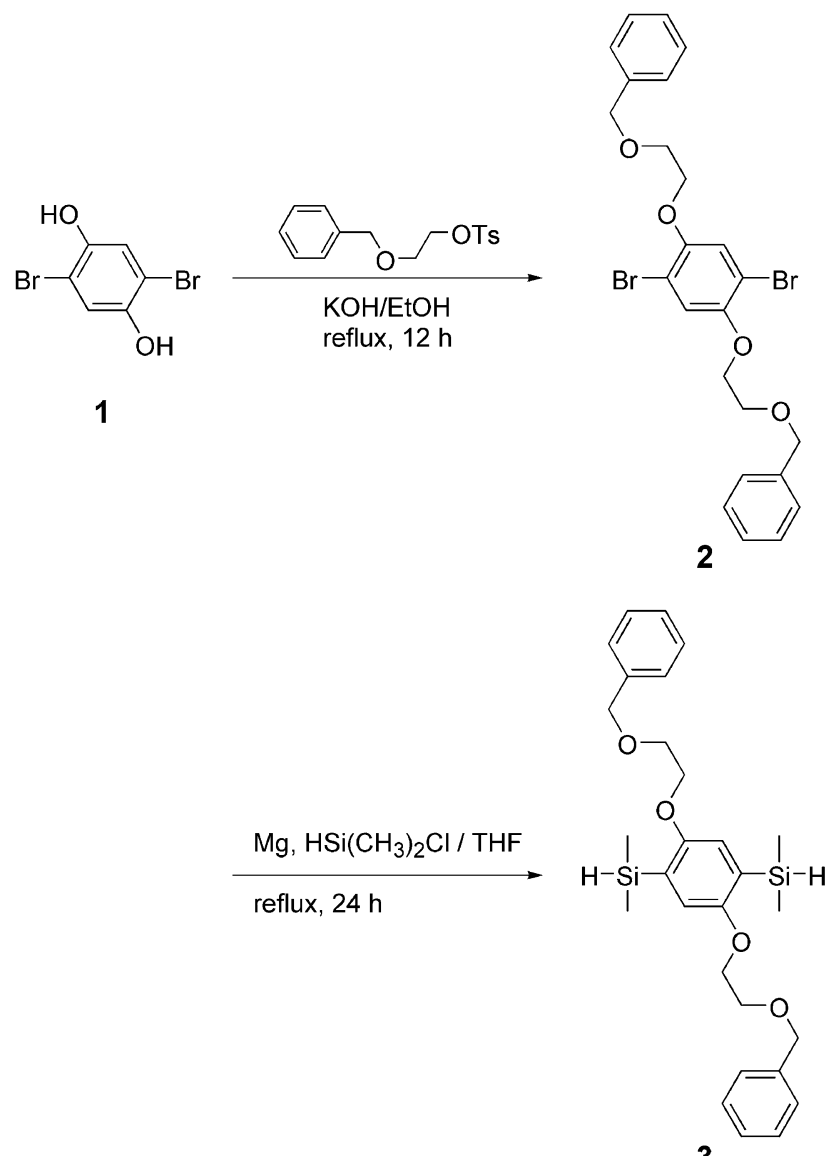

3

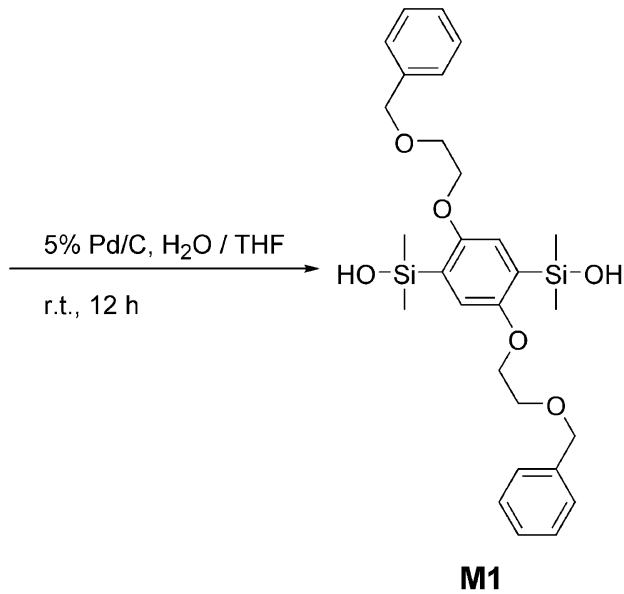

Scheme 2. Synthetic pathways for 2,5-bis(2-benzyloxyethoxy)-1,4-bis(dimethylhydroxsilyl)benzene (M1).

$\left.-\mathrm{CH}_{2}-\right), 3.75-3.95\left(4 \mathrm{H}, \mathrm{m}\right.$, ethoxy $\left.-\mathrm{CH}_{2}-\right), 4.72(2 \mathrm{H}, \mathrm{t}$, $\left.J=5.2 \mathrm{~Hz},-\mathrm{CH}_{2}-\mathrm{OH}\right), 6.95(2 \mathrm{H}, \mathrm{s}$, phenylene protons). ${ }^{13} \mathrm{C}$ NMR $\delta$ [ppm, $\left.\left(\mathrm{CD}_{3}\right)_{2} \mathrm{SO}, 100 \mathrm{MHz}\right]: 1.6\left(\mathrm{Si}-\mathrm{CH}_{3}\right), 59.7$ (ethoxy $-\mathrm{CH}_{2}-$ ), 69.5 (ethoxy $-\mathrm{CH}_{2}-$ ), 116.3 (phenyl carbons), 129.4 (phenyl carbons), 156.5 (phenyl carbons). IR (Film on $\mathrm{KBr}, \mathrm{cm}^{-1}$ ): 3500-3000 (br, $-\mathrm{OH}$ ), 1251 (aromatic ether), $1080(\mathrm{Si}-\mathrm{O})$. 

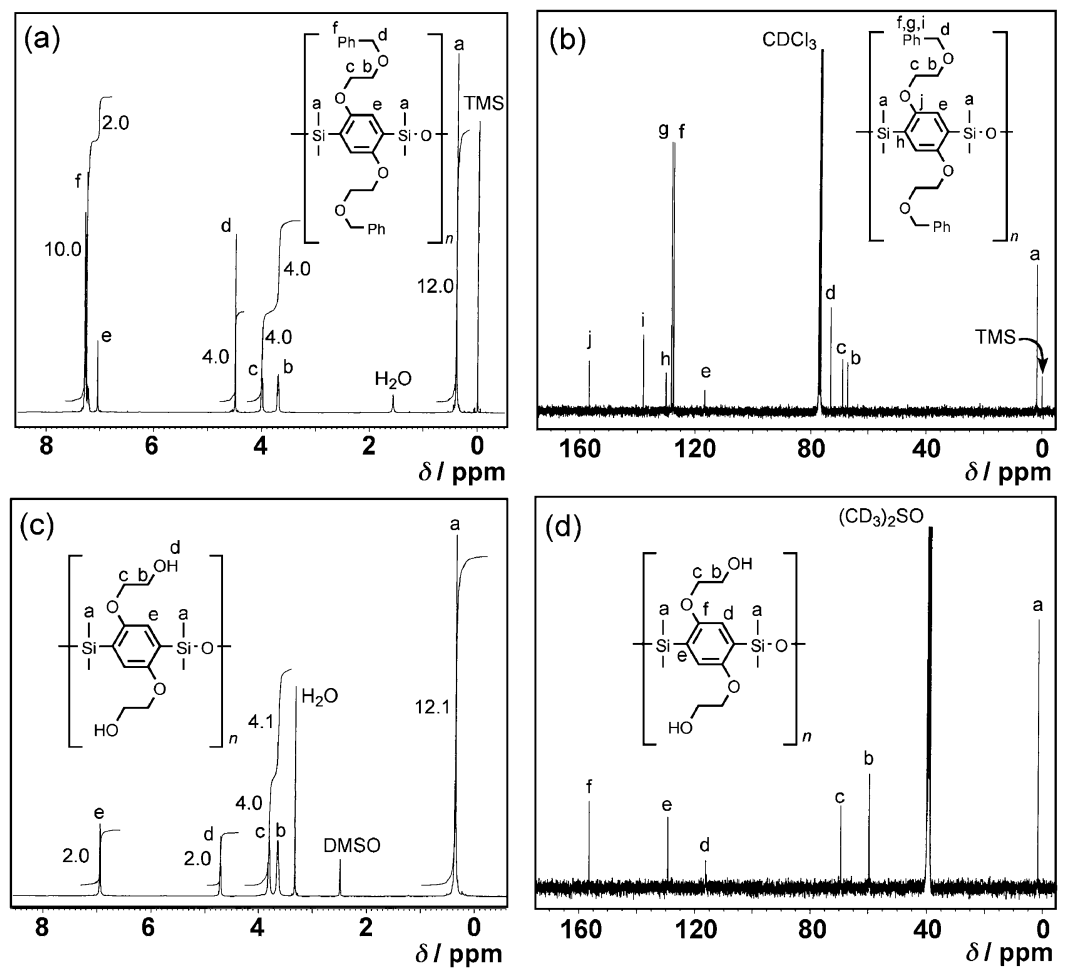

Figure 1. (a) ${ }^{1} \mathrm{H}$ NMR (solvent: $\mathrm{CDCl}_{3}, 400 \mathrm{MHz}$ ) and (b) ${ }^{13} \mathrm{C}$ NMR spectra (solvent: $\mathrm{CDCl}_{3}, 100 \mathrm{MHz}$ ) of PreP1; (c) ${ }^{1} \mathrm{H}$ NMR [ $\left[\mathrm{Solvent}\left(\mathrm{CD}_{3}\right)_{2} \mathrm{SO}, 400 \mathrm{MHz}\right.$ and (d) ${ }^{13} \mathrm{C}$ NMR spectra [solvent: $\left(\mathrm{CD}_{3}\right)_{2} \mathrm{SO}, 100 \mathrm{MHz}$ of $\mathbf{P} 1$ at ambient temperature.

\section{RESULTS AND DISCUSSION}

\section{Synthesis of Monomer}

Scheme 2 shows the pathways for the synthesis of 2,5-bis(2benzyloxyethoxy)-1,4-bis-(dimethylhydroxysilyl)benzene (M1).

It is general that alcoholic-hydroxyl groups are protected by some appropriate protective group in the Grignard reaction to avoid destruction $^{22}$ of the Grignard reagents by hydroxyl moieties. On the other hand, siloxane bondings tend to be cleaved by acidic or basic condition for their ionic properties. ${ }^{1,23}$ Thus, protective groups which should be deprotected in acidic or basic condition could not be applied in the present study. Consequently, we protected an alcoholic-hydroxyl group by a benzyl moiety, which has been reported to be cleaved by certain catalytic hydrogenation to regenerate a hydroxyl group..$^{15,19,24}$

With these in mind, M1 was synthesized by the hydrolysis of 2,5-bis(2-benzyloxyethoxy)-1,4-bis(dimethylsilyl)benzene (3), which had been obtained by the Grignard reaction of 2,5-bis(2-benzyloxyethoxy)-1,4-dibromobenzene (2) with chlorodimethylsilane. The spectroscopic data described in the Experimental part indicated the achievement of the synthesis of a novel monomer.

\section{Synthesis of Polymer}

The polycondensation of M1 catalyzed by 1,1,3,3-tetramethylguanidinium 2-ethylhexanoate was carried out in dry benzene with reflux for $24 \mathrm{~h}$ to afford poly[2,5-bis(2-benzyl- oxyethoxy)-tetramethyl-1,4-silphenylenesiloxane] (PreP1). Any solvent forming azeotropic mixtures with water and dissolving both monomer and the resulting polymer, such as benzene and toluene, can be used for the polycondensation of M1, as observed in the similar polycondensation of disilanol monomers. ${ }^{8-11,14,15}$ The structure of PreP1 was confirmed by ${ }^{1} \mathrm{H}$ and ${ }^{13} \mathrm{C}$ NMR as well as IR spectroscopy.

The catalytic hydrogenation of PreP1 was carried out in the mixed solvent of THF/ethanol $(9 / 1 \mathrm{v} / \mathrm{v})$ to afford poly[2,5bis(2-hydroxyethoxy)-tetramethyl-1,4-silphenylenesiloxane] (P1). Benzyl groups were successfully removed by use of $10 \%$ Pd on C (Degussa type E101 NE/W) as a catalyst for the hydrogenation using a balloon to afford P1 from PreP1, which was confirmed by ${ }^{1} \mathrm{H}$ as well as ${ }^{13} \mathrm{C}$ NMR spectroscopy as depicted in Figure 1.

It can be seen from Figure 1(a) that the ${ }^{1} \mathrm{H}$ NMR spectrum of PreP1 showed the signals at around 7.25-7.35 and at $4.50 \mathrm{ppm}$ assignable to benzyl groups. The ${ }^{13} \mathrm{C}$ NMR spectrum of PreP1 also showed the signals at around 120-140 and at 73.2 ppm based on benzyl groups as shown in Figure 1(b). On the other hand, the signals based on benzyl groups completely disappeared; and instead, a signal at $4.72 \mathrm{ppm}$ based on alcoholic-hydroxyl groups was observed in the ${ }^{1} \mathrm{H} \mathrm{NMR}$ spectrum of $\mathbf{P 1}$ as shown in Figure 1(c). In the ${ }^{13} \mathrm{C} N M R$ spectrum of P1 [Figure 1(d)], three signals based on dimethylsilyl substituted phenylene moieties at 116.3, 129.4, and $156.5 \mathrm{ppm}$, whereas the signals based on benzyl groups completely disappeared. In addition, the broad absorption band based on the alcoholic-hydroxyl groups was observed at around 


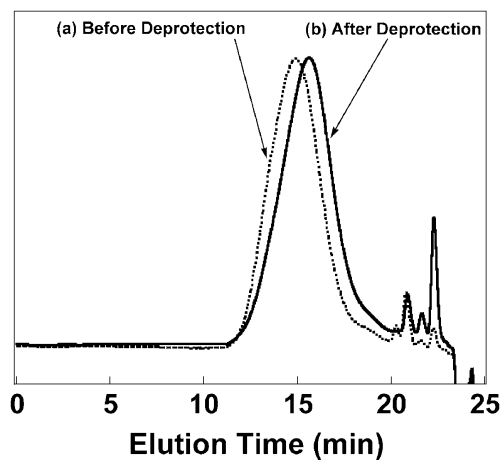

Figure 2. SEC profiles before and after deprotective hydrogenation: (a) PreP1 (dotted line; $M_{\mathrm{n}}=9.83 \times 10^{4}, M_{\mathrm{w}} / M_{\mathrm{n}}=2.54$ ), (b) P1 (line; $M_{\mathrm{n}}=6.39 \times 10^{4}, M_{\mathrm{w}} / M_{\mathrm{n}}=2.83$ )

$3500-3000 \mathrm{~cm}^{-1}$ in the IR spectrum of P1. Thus, it was confirmed that the removal of benzyl groups from PreP1 was completely attained to afford $\mathbf{P 1}$.

Figure 2 depicts the SEC profiles before and after catalytic hydrogenation of PreP1.

Both SEC profiles of PreP1 and P1 were unimodal and seemed to be similar in shape. Supposing there are no significant differences between the conformations of PreP1 and those of $\mathbf{P 1}$ in THF eluent, the $M_{\mathrm{n}}$ of $\mathbf{P 1}$ is expected to be $6.35 \times 10^{4}$ after the complete removal of benzyl groups from a calculation using the $M_{\mathrm{n}}$ of PreP1, i.e., $9.83 \times 10^{4}$. Actually, the $M_{\mathrm{n}}$ of $\mathbf{P 1}$ was estimated to be $6.39 \times 10^{4}$ from SEC measurement and almost equaled the expected $M_{\mathrm{n}}$ as mentioned above. These findings strongly supported that the present catalytic hydrogenation proceeded without side reactions such as the cleavage of the main chains.

\section{Characterization of Polymer}

Table I summarizes the characterization of PreP1 and P1. Figure 3 depicts the DSC traces of PreP1 on the first as well as second heating scan and those of $\mathbf{P 1}$ on the first cooling as well as second heating scan under a nitrogen atmosphere.

An endothermic peak was observed on the first as well as second heating scan of PreP1 at $108^{\circ} \mathrm{C}$ as depicted in Figure 3(a), presumably indicating the crystallinity of PreP1 as observed in 1,4-PTMPS derivatives with 2-methoxyethoxy or 2-(2-methoxyethoxy)ethoxy groups on the phenylene moieties. ${ }^{14}$ The broad exothermic peaks observed on a second heating scan of PreP1 at around $40-60{ }^{\circ} \mathrm{C}$ would be based on

Table I. Characterization of PreP1 and P1

\begin{tabular}{cccccc}
\hline Polymer & $10^{-4} M_{\mathrm{n}}{ }^{\mathrm{a}}$ & $M_{\mathrm{w}} / M_{\mathrm{n}}{ }^{\mathrm{b}}$ & $T_{\mathrm{g}}\left({ }^{\circ} \mathrm{C}\right)^{\mathrm{c}}$ & $T_{\mathrm{m}}\left({ }^{\circ} \mathrm{C}\right)^{\mathrm{d}}$ & $T_{\mathrm{d} 5}\left({ }^{\circ} \mathrm{C}\right)^{\mathrm{e}}$ \\
\hline PreP1 & 9.83 & 2.54 & 76 & 108 & 343 \\
P1 & 6.39 & 2.83 & 73 & $-{ }^{\mathrm{f}}$ & 290 \\
\hline
\end{tabular}

aNumber-average molecular weight estimated from SEC eluted with THF based on polystyrene standards. ${ }^{b}$ Polydispersity index. ${ }^{\circ}$ Glass transition temperature determined by differential scanning calorimetry (DSC) under a nitrogen atmosphere. ${ }^{\mathrm{d}}$ Melting temperature determined by differential scanning calorimetry (DSC) under a nitrogen atmosphere. ${ }^{\mathrm{e}}$ Temperature at $5 \%$ weight loss determined by thermogravimetry (TG) under a nitrogen atmosphere. ${ }^{f}$ Not observed.
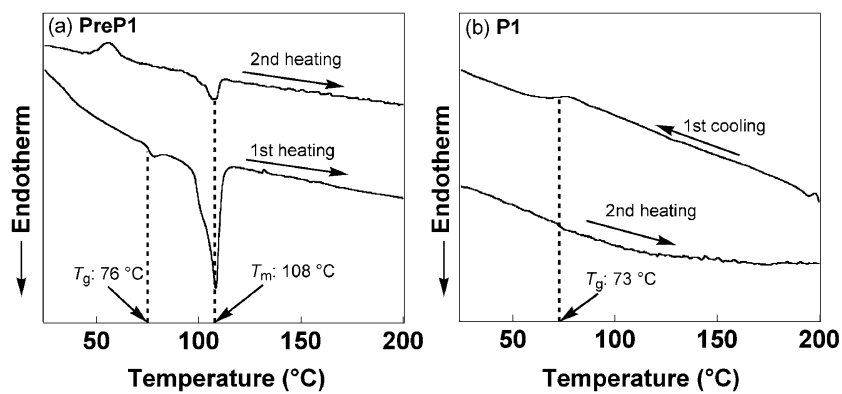

Figure 3. DSC traces of (a) PreP1 on a first heating scan at a heating rate of $10^{\circ} \mathrm{C} / \mathrm{min}$ as well as a second heating scan at a heating rate of $2^{\circ} \mathrm{C} / \mathrm{min}$; and (b) $\mathbf{P 1}$ on a first cooling scan at a cooing rate of $10^{\circ} \mathrm{C} / \mathrm{min}$ as well as a second heating scan at a heating rate of $2{ }^{\circ} \mathrm{C} / \mathrm{min}$ under a nitrogen flow rate of $10 \mathrm{~mL} / \mathrm{min}$.

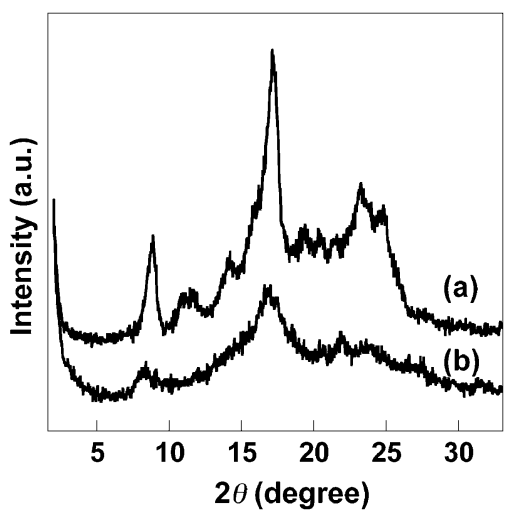

Figure 4. X-Ray diffraction patterns of (a) PreP1 and (b) P1 at ambient temperature.

the progress of crystallization. It is presumably due to the low degree of crystallization that the endotherm observed in the second heating scan was smaller than that done in the first heating scan. In contrast, no endothermic peaks were observed in the first and second heating scans of P1, presumably indicating that $\mathbf{P 1}$ is an amorphous polymer.

For investigating the crystallinity of PreP1 and P1, we carried out the X-ray diffraction analyses of PreP1 and P1. Figure 4 shows the X-ray diffraction patterns of PreP1 and P1 at ambient temperature.

Some peaks were observed in the X-ray diffraction pattern of PreP1, indicating that PreP1 possesses the crystallinity. The diffraction peaks at around $8.9,11.7,14.1$ and $17.3^{\circ}$ in the X-ray diffraction pattern of PreP1 correspond to the $d$-spacing of $c a .0 .99,0.76,0.63$, and $0.51 \mathrm{~nm}$, respectively. Therefore, the endothermic peak at $108^{\circ} \mathrm{C}$ observed in the DSC trace of PreP1 as depicted in Figure 3(a) was conclusively due to the melting, and the melting temperature $\left(T_{\mathrm{m}}\right)$ of PreP1 has been determined to be $108{ }^{\circ} \mathrm{C}$ as mentioned above. In contrast, there are no sharp diffraction peaks in the X-ray diffraction pattern of $\mathbf{P 1}$, indicating that $\mathbf{P 1}$ is an amorphous polymer as deduced from the DSC measurement.

The $T_{\mathrm{g}} \mathrm{s}$ of PreP1 and P1 were also summarized in Table I. The $T_{\mathrm{g}}$ of PreP1 could be determined to be $76^{\circ} \mathrm{C}$ from the first 


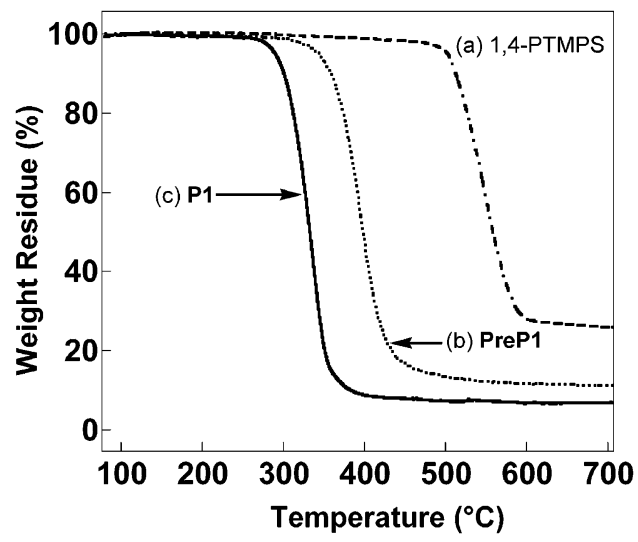

Figure 5. TG curves for (a) 1,4-PTMPS, (b) PreP1, and (c) P1 at a heating rate of $10^{\circ} \mathrm{C} / \mathrm{min}$ under a nitrogen atmosphere.

heating scan as shown in Figure 3(a), and that of P1 could be done to be $73^{\circ} \mathrm{C}$ from the second heating as well as the first cooling scan as shown in Figure 3(b). The $T_{\mathrm{g}}$ of PreP1 was higher than that of 1,4-PTMPS, which has been reported to be $-20{ }^{\circ} \mathrm{C},{ }^{3}$ indicating that the introduction of bulky benzyloxyethoxy groups in the side chain would inhibit the backbone mobility and make $T_{\mathrm{g}}$ high. Meanwhile, the $T_{\mathrm{g}}$ of P1 was also higher than 1,4-PTMPS, whereas the bulky benzyl groups were absent, indicating that the intermolecular and/or intramolecular hydrogen bondings based on hydroxyl groups would restrict the mobility of the main chain and make $T_{\mathrm{g}}$ high. ${ }^{15,25,26}$

Figure 5 depicts the TG curves for PreP1 and P1 as well as 1,4-PTMPS under a nitrogen atmosphere. The temperatures at $5 \%$ weight loss $\left(T_{\mathrm{d} 5} \mathrm{~s}\right)$ of PreP1 and P1 determined by TG under a nitrogen atmosphere are also summarized in Table I.

The $T_{\mathrm{d} 5} \mathrm{~S}$ of PreP1 and P1 were determined to be $343^{\circ} \mathrm{C}$ and $290^{\circ} \mathrm{C}$, respectively, which were low compared with the $T_{\mathrm{d} 5}$ of 1,4-PTMPS $\left(c a .500^{\circ} \mathrm{C}\right) .^{3,8,9}$ It would be attributed to the difference in the bond energies between $\mathrm{Si}-\mathrm{O}$ and $\mathrm{C}-\mathrm{O}$ bondings that the $T_{\mathrm{d} 5}$ of PreP1 was lower than that of 1,4PTMPS. PreP1 involves ether linkages at the benzyloxy moiety. The bond energy of $\mathrm{C}-\mathrm{O}$ has been reported ${ }^{3}$ to be $358 \mathrm{~kJ} / \mathrm{mol}$, which is lower than that of $\mathrm{Si}-\mathrm{O}(444 \mathrm{~kJ} / \mathrm{mol})$, resulting in the lower $T_{\mathrm{d} 5}$ of PreP1 than that of 1,4-PTMPS. It would be because the chemical species generated by the decomposition of the side-chain ether linkages promoted the decomposition of the main chain that the decomposition of the main chain with the high bond energy occurred together with that of the side-chain oxyethylene moieties. On the other hand, it would be presumably because the phenolic moieties were readily generated by the decomposition of 2-hydroxyethylether moieties on the phenylene moieties that the $T_{\mathrm{d} 5}$ of $\mathbf{P 1}$ was lower than those of PreP1 and 1,4-PTMPS. It has been reported $^{25}$ that the intermolecular and/or intramolecular interactions between the side-chain carboxyl groups and $\mathrm{Si}-\mathrm{O}$ moieties in the main chain through hydrogen bonding. In the present system, there could be the intermolecular and/or intramolecular interactions between the side-chain phenolic
Table II. Solubility of PreP1 and P1 ${ }^{\mathrm{a}}$

\begin{tabular}{lccc}
\hline Solvent & 1,4-PTMPS & PreP1 & P1 \\
\hline Acetone & - & \pm & - \\
Benzene & + & + & - \\
Chloroform & + & + & - \\
Dichloromethane & + & + & - \\
Diethylether & + & - & - \\
Dimethylsulfoxide & - & \pm & + \\
$N, N$-Dimethylformamide & \pm & + & + \\
Ethanol & - & - & + \\
Ethyl acetate & \pm & + & - \\
Hexane & - & - & - \\
Methanol & - & - & + \\
Tetrahydrofuran & + & + & + \\
Toluene & + & + & - \\
Water & - & - & - \\
\hline
\end{tabular}

a In the table, + means soluble, \pm means turbid at room temperature, - means insoluble. ${ }^{b}$ Poly(tetramethyl-1,4-silphenylenesiloxane).

moieties generated by the decomposition of 2-hydroxyethylether moieties and Si-O moieties in the main chain, although the acidity of the phenolic moieties are considered to be lower than that of carboxylic moieties. Thus, the phenolic moieties with the low acidity could cause the intermolecular and/or intramolecular interactions with ionic Si-O bondings in the main chain to promote the decomposition of polymer chains and to decline the thermal stability of P1.

Table II summarizes the solubility of 1,4-PTMPS, PreP1, and $\mathbf{P 1}$ in various solvents.

PreP1 exhibited the almost similar solubility in solvents as 1,4-PTMPS. PreP1 is soluble in common organic solvents such as THF, chloroform, dichloromethane, ethyl acetate, and toluene. P1 as well as PreP1 and 1,4-PTMPS are soluble in THF; however, $\mathbf{P 1}$ is also soluble in highly polar solvents as ethanol and methanol in which PreP1 and 1,4-PTMPS are insoluble. The introduction of highly polar hydroxyl groups on the phenylene moiety would allow $\mathbf{P 1}$ to be dissolved in highly polar solvents. On the contrary, $\mathbf{P 1}$ is insoluble in the solvents with low polarity such as chloroform, dichloromethane, benzene, and toluene where PreP1 and 1,4-PTMPS are soluble.

\section{CONCLUSIONS}

Synthesis of novel poly[2,5-bis(2-hydroxyethoxy)-tetramethyl-1,4-silphenylenesiloxane] (P1) was attained by deprotective hydrogenation of poly[2,5-bis(2-benzyloxyethoxy)tetramethyl-1,4-silphenylenesiloxane] (PreP1) catalyzed by $10 \%$ palladium on charcoal. The obtained $\mathbf{P 1}$ was an amorphous polymer and soluble in highly polar solvents as ethanol and methanol in which PreP1 and 1,4-PTMPS are insoluble. The $T_{\mathrm{g}}$ of $\mathbf{P 1}$ was much higher than that of 1,4PTMPS, indicating that the intermolecular and/or intramolecular hydrogen bondings based on hydroxyl groups restricted the mobility of the main chain. The $T_{\mathrm{d} 5}$ of $\mathbf{P 1}$ was lower than that of 1,4-PTMPS; however, the obtained P1 would promise to be a new reactive-polymer with hydroxyl moieties to develop new functional polymers. 
Acknowledgment. This work was partly supported by the Japan Science and Technology Agency through Research for Promoting Technological Seeds (No. 03-066). The authors would like to appreciate Ms. Satoko Tokiwa and Ms. Nami Sugashima, Nihon University College of Engineering Worldwide Research Center for Advanced Engineering \& Technology (NEWCAT), for performing NMR measurements.

Received: June 6, 2008 Accepted: June 20, 2008 Published: July 30, 2008

\section{REFERENCES}

1. a) J. E. Mark, in "Silicon-Based Polymer Science," J. M. Ziegler and F. W. Gordon, Ed., Advances in Chemistry Series 224, American Chemical Society, Washington, DC, 1990, p 47.

b) M. A. Brook, in "Silicon in Organic, Organometallic, and Polymer Chemistry," John Wiley \& Sons, Inc., New York, 2000, chap. 9, p 256.

2. a) Y. Duan, E. M. Pearce, T. K. Kwei, X. Hu, M. Raifairovich, J. Sokolov, K. Zhou, and S. Schwarz, Macromolecules, 34, 6761 (2001).

b) M. A. Grunlan, N. S. Lee, G. Cai, T. Gädda, J. M. Mabry, F. Mansfeld, E. Kus, D. E. Wendt, G. L. Kowalke, J. A. Finlay, J. A. Callow, M. E. Callow, and W. P. Weber, Chem. Mater., 16, 2433 (2004).

3. a) P. R. Dvornic and R. W. Lenz, in "High Temperature Siloxane Elastomers," Hüthig \& Wepf Verlag, Basel, Heiderberg, New York, 1990, chap. III, p 85.

b) G. M. Day, A. I. Hibberd, J. Habsuda, and G. J. Sharp, in "Synthesis and Properties of Silicones and Silicone-modified Materials," S. J. Clarson, J. J. Fitzgerald, M. J. Owen, S. D. Smith, and M. E. van Dyke, Ed., ACS Symposium Series 838, American Chemical Society, Washington, DC, 2003, p 127.

4. R. L. Merker and M. J. Scott, J. Polym. Sci. Part A, 2, 15 (1964).

5. H. N. Beck and R. G. Chaffee, J. Chem. Eng. Data, 8, 602 (1963).

6. Y. Li and Y. Kawakami, Macromolecules, 32, 8768 (1999).

7. J.-Y. Moon, T. Miura, I. Imae, D.-W. Park, and Y. Kawakami, Silicon Chem., 1, 139 (2002).

8. Y. Otomo, Y. Nagase, and N. Nemoto, Polymer, 46, 9714 (2005).
9. I. Sato, S. Takeda, Y. Arai, H. Miwa, Y. Nagase, and N. Nemoto, Polym. Bull., 59, 607 (2007).

10. Y. Hattori, T. Miyajima, M. Sakai, Y. Nagase, and N. Nemoto, Polymer, 49, 2825 (2008).

11. N. Nemoto, T. Yamaguchi, Y. Ozawa, M. Nigorikawa, Y. Yanai, and Y. Nagase, Polym. Bull., in press, DOI: 10.1007/s00289-008-0944-4.

12. H. Ito, E. Akiyama, Y. Nagase, A. Yamamoto, and S. Fukui, Polym. J., 38, 109 (2006).

13. R. Zhang, A. R. Pinhas, and J. E. Mark, Macromolecules, 30, 2513 (1997).

14. N. Nemoto, Y. Watanabe, J. Umemiya, and Y. Otomo, Polym. Bull., 57, 661 (2006).

15. Y. Niwa, S. Kouno, W. Sayama, and N. Nemoto, J. Polym. Sci., Part A: Polym. Chem., 46, 692 (2008).

16. L. Xue and Y. Kawakami, Polym. J., 39, 379 (2007).

17. a) T. Kato and J. M. J. Fréchet, J. Am. Chem. Soc., 111, 8533 (1989) b) T. Kato and J. M. J. Fréchet, Macromolecules, 22, 3818 (1989). c) T. Kato, in "Molecular Self-Assembly Organic Versus Inorganic Approaches,” M. Fujita, Ed., Structure \& Bonding 96, Springer, Berlin, Heidelberg, 2000, p 95.

d) T. Kato, N. Mizoshita, and K. Kanie, Macromol. Rapid Commun., 22, 797 (2001).

18. a) P. Gestoso and J. Brisson, Polymer, 44, 7765 (2003).

b) C. L. Aronson, D. Beloskur, I. S. Frampton, J. McKie, and B. Burland, Polym. Bull., 53, 413 (2005).

19. a) X. Wang, R. Zhuo, L. Liu, F. He, and G. Liu, J. Polym. Sci., Part A: Polym. Chem., 40, 70 (2002).

b) H. Mei, Z. Zhong, F. Long, and R. Zhuo, Macromol. Rapid Commun., 27, 1894 (2006).

c) M. Leemhuis, C. F. van Nostrum, J. A. W. Kruijtzer, Z. Y. Zhong, M. R. ten Breteler, P. J. Dijkstra, J. Feijen, and W. E. Hennink, Macromolecules, 39, 3500 (2006).

20. A. Pelter, I. Jenkins, and D. E. Jones, Tetrahedron, 53, 10357 (1997).

21. M. Ouchi, Y. Inoue, T. Kanzaki, and T. Hakushi, J. Org. Chem., 49, 1408 (1984).

22. B. J. Wakefield, in "Organomagnesium methods in organic synthesis," Academic Press, London, 1995, p 185.

23. N. Nemoto, T. Yotsuya, S. Aoyagi, Y. Ueno, K. Ikeda, and N. Takamiya, Makromol. Chem., 191, 497 (1990).

24. G. Büchi and S. M. Weinreb, J. Am. Chem. Soc., 93, 746 (1971).

25. M. Ohyanagi, K. Ikeda, and Y. Sekine, Makromol. Chem., Rapid Commun., 4, 795 (1983).

26. N. Nemoto, T. Yotsuya, S. Aoyagi, Y. Ueno, K. Ikeda, and N. Takamiya, Polym. Commun., 31, 65 (1990). 